\title{
Glucocorticoids promote neural progenitor cell proliferation derived from human induced pluripotent stem cells
}

\author{
Eiichi Ninomiya ${ }^{1}$, Taeka Hattori ${ }^{1}$, Masashi Toyoda ${ }^{2}$, Akihiro Umezawa ${ }^{3}$, Takashi Hamazaki ${ }^{1}$ and Haruo Shintaku ${ }^{1 *}$
}

\begin{abstract}
Glucocorticoids (GCs) are frequently used for treating and preventing chronic lung disease and circulatory dysfunction in premature infants. However, there is growing concern about the detrimental effects of systemic GC administration on neurodevelopment. The first choice of GCs to minimize the adverse effects on the developing brain is still under debate. We investigated the effect of commonly used GCs such as dexamethasone (DEX), betamethasone (BET) and hydrocortisone (HDC) on the proliferation of human-induced pluripotent stem cell (iPSC)-derived neuronal progenitor cells (NPCs). In this study, NPCs were treated with various concentrations of GCs and subjected to cell proliferation assays. Furthermore, we quantified the number of microtubule-associated protein 2 (MAP2) positive neurons in NPCs by immunostaining. All GCs promoted NPC proliferation in a dose-dependent manner. We also confirmed that MAP2-positive neurons in NPCs increased upon GC treatment. However, differential effects of GCs on MAP2 positive neurons were observed when we treated NPCs with $\mathrm{H}_{2} \mathrm{O}_{2}$. The total numbers of NPCs increased upon any GC treatment even under oxidative conditions but the numbers of MAP2 positive neurons increased only by HDC treatment. GCs promoted human iPSCs-derived NPC proliferation and the differential effects of GCs became apparent under oxidative stress. Our results may support HDC as the preferred choice over DEX and BET to prevent adverse effects on the developing human brain.
\end{abstract}

Keywords: Glucocorticoids; Neural progenitor cell; iPSC; Cell culture; Proliferation

\section{Introduction}

In recent years, systemic glucocorticoids (GCs) have frequently been administered to treat and prevent chronic lung disease (CLD), which is also known as bronchopulmonary dysplasia, and circulatory dysfunction in premature infants. GCs administration dramatically improves the outcome of premature infants with established CLD (Halliday et al. 2009, 2010). However, the use of GCs, especially dexamethasone (DEX), for CLD patients is reported to show detrimental effects on the developing brain with subsequent behavioral alterations and cerebral palsy (Murphy et al. 2001; Shinwell et al. 2000; Yeh et al. 2004). Betamethasone (BET) is also reported to impair cerebral blood flow velocities in very premature infants

\footnotetext{
* Correspondence: shintaku@med.osaka-cu.ac.jp

1 Department of Pediatrics, Osaka City University Graduate School of

Medicine, 1-4-3 Asahi-machi, Abeno-ku, Osaka 545-8585, Japan

Full list of author information is available at the end of the article
}

with severe CLD (Cambonie et al. 2008). A few studies have suggested that patients treated with HDC showed no neurological adverse effect (Benders et al. 2009; de Jong et al. 2011; Watterberg et al. 2007), but another study showed that GCs reduced proliferation and induce differentiation of neurons (Aden et al. 2011). The effect of GCs on the developing human brain remains elusive, and randomized clinical trials are required in order to establish better neurological outcomes.

Many studies have been conducted to reveal the mechanisms underlying the adverse effects of GCs. DEX treatment has been shown to decrease brain weight (Kanagawa et al. 2006) and inhibit hippocampal neurogenesis (Kim et al. 2004) in rats. In addition, DEX inhibited the proliferation of embryonic rat neural stem cells (Bose et al. 2010). Duksal et al. (2009) reported that high dose DEX caused brain weight loss due to neuronal apoptosis. Although many animal studies have indicated that GCs suppress the 
proliferation of neuronal cells, it remains unknown how GCs affect neuronal cells in humans.

In the present study, we investigated the effects of commonly used GCs such as DEX, BET and HDC on the proliferation of human iPS cell-derived NPCs, which were used as a model of human embryonic and neonatal NPCs. We further focused on the subpopulation of NPCs that were committed to the neuronal lineage. The effects of GCs on neural cell proliferation were evaluated. We also examined whether oxidative stress affected the sensitivity of NPCs to GCs.

\section{Methods \\ Reagents}

DECADRON $^{\bullet}$ (Dexamethasone) was obtained from MSD (Tokyo, Japan). Rinderon ${ }^{\circ}$ (Betamethasone) was from Shionogi \& Co., Ltd. (Osaka, Japan). Hydrocortone (hydrocortisone) was from Nichi-Iko Pharmaceutical Co., Ltd. (Toyama, Japan). Hydrogen peroxide solution $\left(\mathrm{H}_{2} \mathrm{O}_{2}\right)$ was from Wako Pure Chemical Industries, Ltd. (Osaka, Japan).

Human iPS cell culture and neural progenitor cells induction The study was approved by the Ethics Committees of the Osaka City University (approval \#2472) and was conducted according to the declaration of Helsinki. In this study, we used human iPSCs derived from fetal lung fibroblast (MRC-5) cells and the iPSCs were maintained by standard culture methods as described previously (Saito et al. 2011). Neural induction was performed as described previously (Chambers et al. 2009). Briefly, neural induction will be initiated by $10 \mu \mathrm{M}$ SB431542 (TGF- $\beta$ inhibitor, Wako) and $200 \mathrm{ng} / \mathrm{ml}$ of Noggin (R\&D Systems, Minneapolis, MN). After 8 days of neural induction, cells are dissociated with accutase (Chemicon, Temecula, CA) and plated onto polyornithine and laminin (Sigma, St. Louis, MO) with neurobasal medium supplemented with 2\% B27 (Invitrogen), $20 \mathrm{ng} / \mathrm{ml} \mathrm{bFGF}$ (Wako), $20 \mathrm{ng} / \mathrm{ml}$ epidermal growth factor (EGF, Invitrogen). Rosette neural stem cells (R-NSC) will form within a few days. R-NSCs were enriched by Neural Rosette Selection Reagent ${ }^{\ominus}$ (Stem Cell Technologies, Toronto, Canada). NPCs were obtained after a few passages and subjected to proliferation assays. Schematic diagram of induction of NPCs and representative growth rate of NPCs are shown in Additional file 1: Figure S1.

\section{Proliferation assay}

Cell proliferation was measured using Cell Titer 96 AQueous One Solution cell proliferation assay according to the manufacturer's protocol (Promega, Madison, WI). Ninety-six-well tissue culture plates were coated with poly-ornithine and laminin. NPCs were plated at a density of $6 \times 10^{3}$ cells per well. GCs treatment was started $48 \mathrm{~h}$ after plating. After 4 days of GCs exposure, proliferation assays was performed by adding Cell Titer 96
AQueous One Solution and incubating at $37^{\circ} \mathrm{C}$ for $2 \mathrm{~h}$. Then absorbance was measured at $450 \mathrm{~nm}$ with a micro plate reader (MTP-300:CORONA ELECTRIC).

\section{Immunocytochemistry and MAP2 positive cell count}

Chamber slides, $\mu$-slide IV (Ibidi, Martinsried, Germany) were coated with poly-ornithine and laminin. NPCs were plated in the chamber slides at a density of $1.8 \times 10^{4}$ cells per well and cultured for $48 \mathrm{~h}$, followed by exposure to GCs. After 4 days incubation, cells were subjected for immunostaining. Mouse monoclonal anti-MAP2 antibody (AP20) (Chemicon, Temecula, CA) (1:200), Alexa Fluor ${ }^{\odot}$ 488 Goat Anti-Mouse IgG (Invitrogen) (1:1000), and 4,6diamidino-2-phenylindole (DAPI) (Sigma) were used. For quantification of MAP2 positive cells and DAPI positive cells, 5 microscopic fields were randomly selected and cells were automatically counted using ImageJ (Schneider et al. 2012). Cell counts per field were standardized against untreated cell counts for each experiment.

\section{Statistical analysis}

For statistical analysis, data were evaluated by analysis of variance (Statcel3, add-in software to Microsoft ${ }^{\odot}$ Excel 2007). Differences between groups were analyzed by single-factor ANOVA with Tukey-Kramer. Results are displayed with mean \pm SD. $P$ values $<0.05$ were considered statistically significant. All experiments were repeated more than three times.

\section{Results}

GC treatment promoted neural progenitor cell proliferation

To evaluate the effect of GCs on the proliferation of NPCs, we initially performed a cell proliferation assay. NPCs were exposed to GCs for 4 days and subjected to a proliferation assay. As shown in Figure 1a, the average absorbance of the samples treated with DEX of $5 \mathrm{nM}, 500 \mathrm{nM}$, and $50 \mu \mathrm{M}$ were $107.5 \pm 10.2(P$ value $=\mathrm{NS}), 113.8 \pm 17.1(P$ value $<$ $0.05)$, and $124.0 \pm 8.9(P$ value $<0.01)$, respectively. The samples treated with BET of $5 \mathrm{nM}, 500 \mathrm{nM}$, and $50 \mu \mathrm{M}$ were $108.7 \pm 9.8(P$ value $=\mathrm{NS}), 110.2 \pm 12.4(P$ value $=$ NS), and $114.4 \pm 9.4$ ( $P$ value $<0.01)$, respectively (Figure $1 \mathrm{~b})$. The samples treated with HDC of $5 \mathrm{nM}, 500 \mathrm{nM}$, and $50 \mu \mathrm{M}$ were $105.0 \pm 8.6(P$ value $=\mathrm{NS}), \quad 114.0 \pm 11.3$ $(P$ value $<0.01)$, and $118.4 \pm 9.3(P$ value $<0.01)$, respectively (Figure 1c). We also calculated the $P$ values for comparison of each GC from $5 \mathrm{nM}$ to $50 \mu \mathrm{M}$. Both DEX and HDC showed statistically significant differences on the absorbance between $5 \mathrm{nM}$ and $50 \mu \mathrm{M}(P$ value $<0.01)$.

In summary, our results indicate that the GCs stimulate proliferation of NPCs in a dose-dependent manner. Moreover, the proliferative effect was independent from the types of GCs we tested. 
Figure 1 Glucocorticoid (GC) treatment promoted NPC proliferation. Cell proliferation was measured by absorbance using Cell 96 AQueous One Assay kit. The average absorbance data were expressed as percentages of untreated samples. $P$ values were calculated by comparing with untreated samples $(n=3) .{ }^{*} P<0.05$, ${ }^{*} P<0.01$. (One-way ANOVA with Tukey-Kramer). The cells were treated with the indicated concentration of (a) dexamethasone (DEX), (b) betamethasone (BET), and (c) hydrocortisone (HDC).

\section{GC treatment promoted cell proliferation of MAP2 positive neuron}

GC treatment is reported to increase apoptosis in distinct neural regions in the brain. The studies indicate that neuronal cells are more susceptible than glial cells (Duksal et al. 2009; Hassan et al. 1996). Since iPS cellderived NPCs consist of heterogeneous populations, we focused on proliferation of the cells that were committed to the neuronal lineage in the GC-treated NPCs.

Microtubule-associated protein 2 (MAP2) is specifically expressed in vivo in the granular layer in the embryo (Tucker et al. 1989). We performed immunostaining using an anti-MAP2 antibody to evaluate the number of neuronal lineage cells after GC treatments (Figure 2c). For this experiment, NPCs were exposed to GCs for 4 days and then subjected to analysis.

We compared the MAP2 positive cell count with the untreated NPCs and calculated the $P$ values. As shown in Figure $2 b$, the average numbers of MAP2-positive neurons treated with DEX of $500 \mathrm{nM}$ and $50 \mu \mathrm{M}$ were $125.4 \pm 36.0$ $(P$ value $<0.05)$ and $158.6 \pm 35.3(P$ value $<0.01)$, respectively. The MAP2-positive neurons treated with BET of $500 \mathrm{nM}$ and $50 \mu \mathrm{M}$ were $122.7 \pm 36.0(P$ value $=\mathrm{NS})$ and $173.0 \pm 39.6(P$ value $<0.01)$, respectively (Figure $2 c)$. The MAP2-positive neurons treated with HDC of $500 \mathrm{nM}$ and $50 \mu \mathrm{M}$ were $116.0 \pm 26.1(P$ value $=$ NS $)$ and $145.1 \pm 36.7$ $(P$ value $<0.01)$, respectively (Figure $2 \mathrm{~d}$ ). All GCs showed statistically significant differences on the average numbers of MAP2-positive neurons between $5 \mathrm{nM}$ and $50 \mu \mathrm{M}$ (DEX and HDC showed $P$ value $<0.05$, BET showed $P$ value $<0.01)$. These data indicate that the MAP2 positive cell number significantly increased as the cells were treated with a higher dose of GCs. Moreover, we found no significant differences in proliferative potency between DEX, BET, and HDC.

\section{GC treatment promoted NPC proliferation under oxidative stress}

Involvement of oxidative stress was suggested in the pathogenesis of neonatal CLD (Ogihara et al. 1999) and oxidative stress is thought to be a cause of neuronal damage (Ikonomidou and Kaindl 2011). To mimic clinical situations during the use of GCs, we treated NPCs with $\mathrm{H}_{2} \mathrm{O}_{2}$ for oxidative stress and examined the effect of GCs on NPC proliferation. We have initially tested 

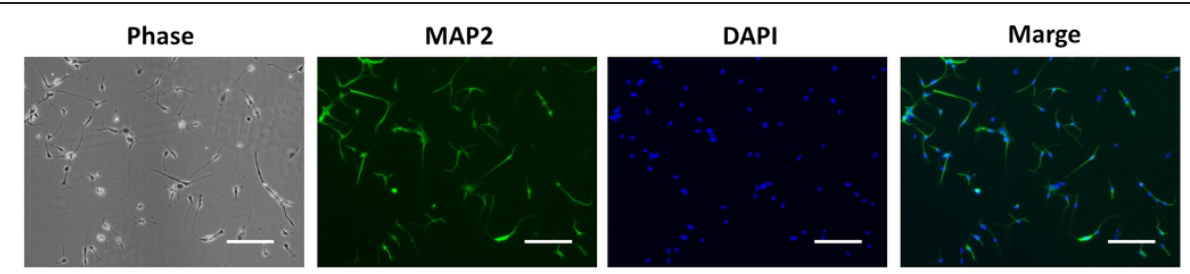

a

b
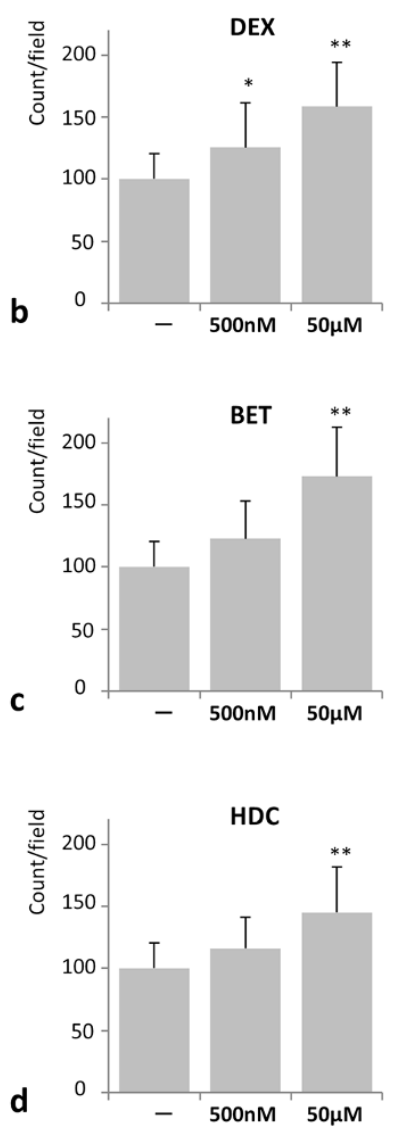

Figure 2 GC treatment promoted cell proliferation of MAP2 positive neurons. (a) Representative pictures of NPCs stained with an antibody against MAP2 (red) and nuclear counterstain DAPI (blue). Phase, phase contrast image. Scale bar, $100 \mu \mathrm{m}$. (b-d). Quantification of MAP2 positive neurons using ImageJ. $P$ values were calculated by comparing GC treated with untreated samples $(n=3)$. ${ }^{*} P<0.05$, ${ }^{*} P<0.01$. (One-way

ANOVA with Tukey-Kramer). The cells were treated with the indicated concentration of (b) dexamethasone (DEX), (c) betamethasone (BET), and (d) hydrocortisone (HDC).

various concentration of $\mathrm{H} 2 \mathrm{O} 2$ on the NPCs without GCs. $300 \mu \mathrm{M}$ H2O2 concentration was reasonably seen the effect of the stress on cellular proliferation (Additional file 2: Figure S2).

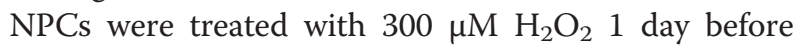
GC treatment. Similarly, we expressed the average absorbance data as percentages of untreated samples, and the mean percent \pm SD of untreated samples was $100 \pm$ 5.0. The results are shown in Figure 3. The average absorbance of cells that were treated only with $\mathrm{H}_{2} \mathrm{O}_{2}$ was $88.8 \pm 7.8$, which is significantly reduced relative to the untreated samples $(P$ value $<0.05$, Figure 3$)$.
Initially, we compared the average absorbance with only $\mathrm{H}_{2} \mathrm{O}_{2}$ treated NPCs and calculated the $P$ values (Figure 3). The average absorbance of the samples treated with DEX of $5 \mathrm{nM}, 500 \mathrm{nM}$, and $50 \mu \mathrm{M}$ under $\mathrm{H}_{2} \mathrm{O}_{2}$-treated condition were $93.8 \pm 10.3(P$ value $=\mathrm{NS})$, 96.6 $\pm 8.0(P$ value $=$ NS $)$, and $124.0 \pm 6.9(P$ value $<0.01)$, respectively. The average absorbance of cells treated with BET of $5 \mathrm{nM}, 500 \mathrm{nM}$, and $50 \mu \mathrm{M}$ under $\mathrm{H}_{2} \mathrm{O}_{2}$ treated condition were $96.0 \pm 8.6(P$ value $=\mathrm{NS}), 103.2 \pm$ $7.6(P$ value $<0.01)$, and $109.4 \pm 2.9(P$ value $<0.01)$, respectively. The average absorbance of cells treated with HDC of $5 \mathrm{nM}, 500 \mathrm{nM}$, and $50 \mu \mathrm{M}$ under $\mathrm{H}_{2} \mathrm{O}_{2}$-treated 


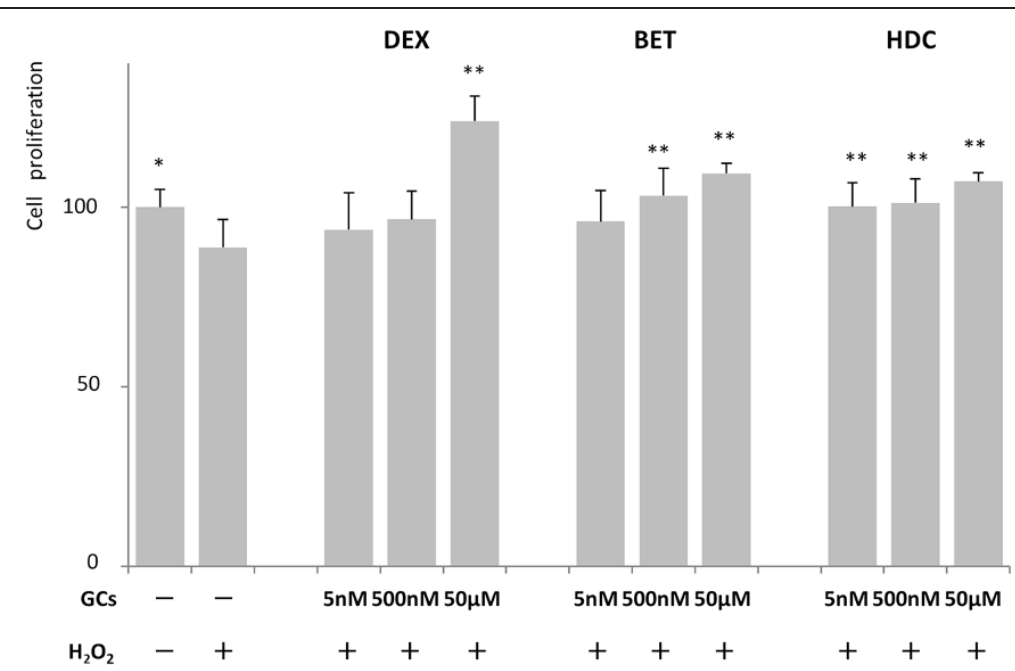

Figure 3 GC treatment promoted NPC proliferation under oxidative stress. Cell proliferation was measured by absorbance using Cell 96 AQueous One Assay kit. The average absorbance data were expressed as percentages of untreated samples. $P$ values were calculated by comparing GC treated with untreated samples $(n=3)$. ${ }^{*} P<0.05$, ${ }^{*} P<0.01$. (One-way ANOVA with Tukey-Kramer). DEX: dexamethasone, BET: betamethasone, HDC: hydrocortisone.

condition were $100.2 \pm 6.6(P$ value $<0.01)$, $101.2 \pm 6.8$ $(P$ value $<0.01)$, and 107.2 $\pm 2.5(P$ value $<0.01)$, respectively. When we compared the average absorbance between each GC in the same concentration with or without $\mathrm{H}_{2} \mathrm{O}_{2}$, we did not observe statistical significance except for DEX at $5 \mathrm{nM}$ and $500 \mathrm{nM}(P$ value $<0.01)$. These data indicate that the absorbance significantly increased as the cells were treated with a higher dose of GCs even under $\mathrm{H}_{2} \mathrm{O}_{2}$-treated condition.

In summary, our results indicate that GCs stimulated the proliferation of NPCs under $\mathrm{H}_{2} \mathrm{O}_{2}$-treated conditions. All examined GCs induced NPC proliferation in a dose dependent manner regardless of oxidative stress.

\section{HDC alone promoted cell proliferation of MAP2 positive neuron under oxidative stress}

Neurons are more sensitive to oxidative stress than any other type of cells in the brain (Hayashi et al. 2012). Therefore, we examined the effects of the GCs on the proliferation of MAP2-positive neurons under an oxidative stress condition. NPCs were treated with $300 \mu \mathrm{M}$ $\mathrm{H}_{2} \mathrm{O}_{2} 1$ day before GC treatment, then NPCs were exposed to GCs for 4 days and subjected to immunostaining using an anti-MAP2 antibody (Figure 4a).

We compared the MAP2 positive cell count with the condition treated with $\mathrm{H}_{2} \mathrm{O}_{2}$ alone $(74.9 \pm 31.8)$. The average numbers of MAP2-positive neurons treated with DEX of $500 \mathrm{nM}$ and $50 \mu \mathrm{M}$ were $75.6 \pm 52.3(P$ value $=$ NS $)$ and $84.7 \pm 27.2(P$ value $=$ NS), respectively. The average numbers of MAP2-positive neurons treated with BET of $500 \mathrm{nM}$ and $50 \mu \mathrm{M}$ were $93.1 \pm 41.1(P$ value $=\mathrm{NS})$ and $113.1 \pm 47.7(P$ value $=$ NS $)$, respectively. The average numbers of MAP2-positive neurons treated with HDC of $500 \mathrm{nM}$ and $50 \mu \mathrm{M}$ were $108.5 \pm 34.0(P$ value $<0.05)$ and $143.6 \pm 19.4$ ( $P$ value $<0.01)$, respectively. Unlike DEX and BET, HDC significantly increased the number of MAP2positive neurons compared with the untreated samples even under the $\mathrm{H}_{2} \mathrm{O}_{2}$-treated condition.

In conclusion, only HDC promoted significant cell proliferation of MAP2 positive neurons as well as the total number of NPCs under oxidative stress. DEX and BET, however, increased the total number of NPCs without increasing MAP2 positive neurons.

\section{Discussion}

In this study, we investigated the effect of GCs on proliferation of NPCs derived from human iPS cells. Unexpectedly, all GCs we tested induced NPC proliferation in a dose dependent manner. We also confirmed that MAP2 positive neuronal cells were increased by GC treatment. Furthermore, we investigated the proliferative effects of GCs under an oxidative stress condition that could be more relevant to the clinical setting. The findings revealed that all GCs stimulated the total number of NPCs even under the oxidative condition, but MAP2 positive neurons were only increased by HDC treatment. Our results support the finding that HDC would be the preferred choice over DEX and BET to prevent adverse effects on the developing brain.

\section{Cell cycle regulation induced by GCs}

Samarasinghe et al. (Samarasinghe et al., 2011) demonstrated that the binding of GCs to the GC receptor (GR) decreased gap junction-mediated intercellular 


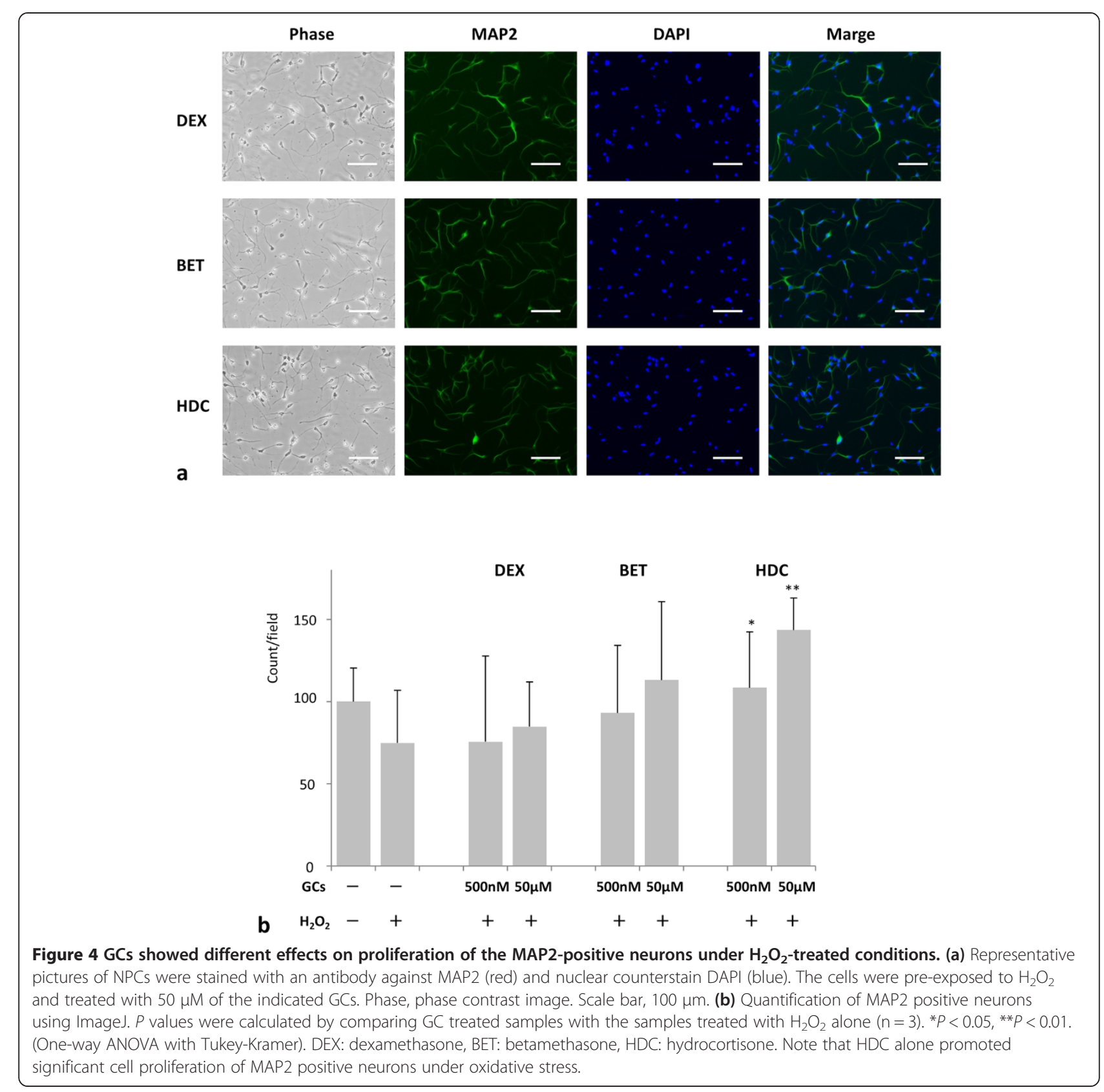

communication and led to a decrease in the rate of cells in the $\mathrm{S}$ phase. They concluded that GC suppresses cell proliferation through this mechanism. Sundberg et al. (2006) reported that the activation of GR prevents cyclin D1-mediated cell cycle progression and that the high dose GC inhibits proliferation of rat embryonic NPCs. Similar inhibitory mechanisms of GCs were reported by others using rodent cells (Bose et al. 2010). Moors et al. (2012) examined the effect of DEX on neurospheres derived from a 16-week human aborted fetus and found that DEX inhibits the proliferation of human NPCs. However, in our experiment using NPCs derived from human iPS cells, all
GCs we tested including DEX intriguingly promoted the proliferation of NPCs.

\section{Neuroprotective effects of GCs}

GCs exhibit protective effects on postmitotic neurons. Harms et al. (2007) showed that GCs induce phosphatidylinositol 3-Akt-kinase-dependent phosphorylation of p21Waf1/Cip1 and it works as a novel anti-apoptotic pathway for postmitotic primary cortical neurons isolated from rats and mice. By in vivo and in vitro studies using the rat model, Jeanneteau et al. (2008) showed that GCs activate the Trk neurotrophin receptor and thus exhibit 
neuroprotective effects. In any case, neuroprotective pathways in postmitotic neurons prevent new cell cycles. Therefore, such a neuroprotective mechanism alone cannot explain how GCs induce NPC proliferation.

\section{Differential mechanisms of action between GCs}

We demonstrated that GCs differently stimulate the proliferation of MAP2-positive neurons under oxidative stress. HDC physically associates with both GR and mineralcorticoid receptor (MR) in vivo, while DEX and BET physically associate only with GR but not with MR (De Kloet et al. 1998). As described above, it has been reported that GR suppresses cell proliferation and causes apoptosis. In the present study, the GCs showed similar effects under nonstressed conditions. Under oxidative stress conditions, however, HDC alone increased the number of MAP2 positive neurons. This may suggest that the activation of MR plays an important role in the proliferation of neurons under oxidative stress. Another possibility could be the difference in the inactivation mechanisms of the GCs. While HDC is metabolized by $11 \beta \mathrm{HSD} 2, \mathrm{DEX}$ and BET are not sensitive to inactivation by 11ßHSD2 (Heine and Rowitch 2009; Noguchi et al. 2011). Thus, the continuous GR activity may induce apoptosis under stress conditions. The human NPCs used in this study were indeed expressing both MR and GR (Additional file 3: Figure S3).

\section{Clinical implications}

Our current study demonstrates that NPCs proliferate in response to GCs but MAP2 positive neurons are sensitive to oxidative stress. It is interesting that the response to HDC is less affected by oxidative stress than DEX or BET (Figure 4). Halliday et al. (2009, 2010) recommended avoiding frequent use of GCs for CLD treatment but there is insufficient evidence regarding which types of GCs to use in order to minimize adverse neurological outcomes. Further clinical and mechanistic studies are required to determine the optimal choice of GCs for children with CLD.

In conclusion, we evaluated the effect of GCs on NPC derived human iPS cells and found unique proliferative effects on NPCs, which were altered by external stress. Further mechanistic studies are needed to reveal how GCs induce NPC proliferation and how oxidative stress modulates the effects of GCs.

\section{Additional files}

Additional file 1: Figure S1. Derivation of neural progenitor cells (NPCs) from human iPS cells. (a) Schematic diagram of induction of NPCs. R-NSC: Rosette neural stem cells. (b) Representative picture of R-NSC and NPCs in phase contrast image. R-NSC stained positive for Nestin (green/insert). Bar:100 $\mu \mathrm{m}$. (c) Growth curve for NPCs. Cell number was automatically measured by using IncuCyte imaging system (Essen BioScience, K.K., Japan)
Additional file 2: Figure S2. Effect of $\mathrm{H}_{2} \mathrm{O}_{2}$ treatment on NPC proliferation under oxidative stress. NPCs were treated various concentration of $\mathrm{H}_{2} \mathrm{O}_{2}$ as indicated. Cell proliferation was measured by absorbance using Cell 96 AQueous One Assay kit. The average absorbance data were expressed as percentages of untreated samples.

Additional file 3: Figure S3. Expression of glucocorticoid receptor and mineral corticoid receptor in NPCs Quantitative RT-PCR analysis was performed on MRC5-iPSC and NPCs. The mRNA values were expressed relative to the control gene ( $\beta$-actin). GR: glucocorticoid receptor, MR: mineral corticoid receptor.

\section{Competing interests}

The authors declare that they have no competing interests.

\section{Authors' contributions}

EN, TH, TH carried out the cell culture studies, and drafted the manuscript MT, AU provided materials and conceived of the study. HS participated in study design, coordination and helped to draft the manuscript. All authors read and approved the final manuscript.

\section{Acknowledgments}

We thank Dr Katherine E Santostefano (University of Florida) for helpful discussion and critical readings of the manuscript. This work was supported by the Japanese Ministry of Education, Culture, Sports, Science, and Technology (TH and HS) and Takeda Science Foundation (TH).

\section{Author details}

1Department of Pediatrics, Osaka City University Graduate School of Medicine, 1-4-3 Asahi-machi, Abeno-ku, Osaka 545-8585, Japan. ${ }^{2}$ Research Team for Geriatric Medicine (Vascular Medicine), Tokyo Metropolitan Institute of Gerontology, Sakaecho 35-2, Itabashi-Ku, Tokyo 173-0015, Japan. ${ }^{3}$ Department of Reproductive Biology, National Research Institute for Child Health and Development, 2-10-1 Ookura, Setagaya-ku, Tokyo 157-8535, Japan.

Received: 25 July 2014 Accepted: 6 September 2014 Published: 15 September 2014

\section{References}

Aden P, Paulsen RE, Maehlen J, Loberg EM, Goverud IL, Liestol K, Lomo J (2011) Glucocorticoids dexamethasone and hydrocortisone inhibit proliferation and accelerate maturation of chicken cerebellar granule neurons. Brain Res 1418:32-41 Benders MJ, Groenendaal F, van Bel F, Ha Vinh R, Dubois J, Lazeyras F, Warfield SK, Huppi PS, de Vries LS (2009) Brain development of the preterm neonate after neonatal hydrocortisone treatment for chronic lung disease. Pediatr Res 66:555-559

Bose R, Moors M, Tofighi R, Cascante A, Hermanson O, Ceccatelli S (2010) Glucocorticoids induce long-lasting effects in neural stem cells resulting in senescence-related alterations. Cell Death Dis 1:e92

Cambonie G, Mesnage R, Milesi C, Pidoux O, Veyrac C, Picaud JC (2008) Betamethasone impairs cerebral blood flow velocities in very premature infants with severe chronic lung disease. J Pediatr 152:270-275

Chambers SM, Fasano CA, Papapetrou EP, Tomishima M, Sadelain M, Studer L (2009) Highly efficient neural conversion of human ES and iPS cells by dual inhibition of SMAD signaling. Nat Biotechnol 27:275-280

de Jong SE, Groenendaal F, van Bel F, Rademaker KJ (2011) Pulmonary effects of neonatal hydrocortisone treatment in ventilator-dependent preterm infants. Int J Pediatr 2011:783893

De Kloet ER, Vreugdenhil E, Oitzl MS, Joels M (1998) Brain corticosteroid receptor balance in health and disease. Endocr Rev 19:269-301

Duksal F, Kilic I, Tufan AC, Akdogan I (2009) Effects of different corticosteroids on the brain weight and hippocampal neuronal loss in rats. Brain Res 1250:75-80

Halliday HL, Ehrenkranz RA, Doyle LW (2009) Late (>7 days) postnatal corticosteroids for chronic lung disease in preterm infants. Cochrane Database Syst Rev (1):CD001145, doi:10.1002/14651858.CD001145.pub2

Halliday HL, Ehrenkranz RA, Doyle LW (2010) Early ( $<8$ days) postnatal corticosteroids for preventing chronic lung disease in preterm infants. Cochrane Database Syst Rev (1):CD001146, doi:10.1002/14651858.CD001145.pub3

Harms C, Albrecht K, Harms U, Seidel K, Hauck L, Baldinger T, Hubner D, Kronenberg G, An J, Ruscher K, Meisel A, Dirnagl U, von Harsdorf R, 
Endres M, Hortnagl H (2007) Phosphatidylinositol 3-Akt-kinase-dependent phosphorylation of p21(Waf1/Cip1) as a novel mechanism of neuroprotection by glucocorticoids. In J Neurosci 27:4562-4571

Hassan AH, von Rosenstiel P, Patchev VK, Holsboer F, Almeida OF (1996) Exacerbation of apoptosis in the dentate gyrus of the aged rat by dexamethasone and the protective role of corticosterone. In Exp Neurol 140:43-52

Hayashi M, Miyata R, Tanuma N (2012) Oxidative stress in developmental brain disorders. Adv Exp Med Biol 724:278-290

Heine VM, Rowitch DH (2009) Hedgehog signaling has a protective effect in glucocorticoid-induced mouse neonatal brain injury through an 11 betaHSD2-dependent mechanism. J Clin Invest 119:267-277

Ikonomidou C, Kaindl AM (2011) Neuronal death and oxidative stress in the developing brain. Antioxid Redox Signal 14:1535-1550

Jeanneteau F, Garabedian MJ, Chao MV (2008) Activation of Trk neurotrophin receptors by glucocorticoids provides a neuroprotective effect. Proc Natl Acad Sci U S A 105:4862-4867

Kanagawa T, Tomimatsu T, Hayashi S, Shioji M, Fukuda H, Shimoya K, Murata Y (2006) The effects of repeated corticosteroid administration on the neurogenesis in the neonatal rat. Am J Obstet Gynecol 194:231-238

Kim JB, Ju JY, Kim JH, Kim TY, Yang BH, Lee YS, Son H (2004) Dexamethasone inhibits proliferation of adult hippocampal neurogenesis in vivo and in vitro. Brain Res 1027:1-10

Moors M, Bose R, Johansson-Haque K, Edoff K, Okret S, Ceccatelli S (2012) Dickkopf 1 mediates glucocorticoid-induced changes in human neural progenitor cell proliferation and differentiation. In Toxicol Sci 125:488-495

Murphy BP, Inder TE, Huppi PS, Warfield S, Zientara GP, Kikinis R, Jolesz FA, Volpe JJ (2001) Impaired cerebral cortical gray matter growth after treatment with dexamethasone for neonatal chronic lung disease. Pediatrics 107:217-221

Noguchi KK, Lau K, Smith DJ, Swiney BS, Farber NB (2011) Glucocorticoid receptor stimulation and the regulation of neonatal cerebellar neural progenitor cell apoptosis. Neurobiol Dis 43:356-363

Ogihara T, Hirano K, Morinobu T, Kim HS, Hiroi M, Ogihara H, Tamai H (1999) Raised concentrations of aldehyde lipid peroxidation products in premature infants with chronic lung disease. Arch Dis Child Fetal Neonatal Ed 80:21-25

Saito S, Onuma Y, Ito Y, Tateno H, Toyoda M, Hidenori A, Nishino K, Chikazawa E, Fukawatase Y, Miyagawa Y, Okita H, Kiyokawa N, Shimma Y, Umezawa A, Hirabayashi J, Horimoto K, Asashima M (2011) Possible linkages between the inner and outer cellular states of human induced pluripotent stem cells. BMC Syst Biol 5(Suppl 1):S17

Samarasinghe RA, Di Maio R, Volonte D, Galbiati F, Lewis M, Romero G, DeFranco DB (2011) Nongenomic glucocorticoid receptor action regulates gap junction intercellular communication and neural progenitor cell proliferation. Proc Natl Acad Sci U S A 108:16657-16662

Schneider CA, Rasband WS, Eliceiri KW (2012) NIH Image to ImageJ: 25 years of image analysis. Nat Methods 9:671-675

Shinwell ES, Karplus M, Reich D, Weintraub Z, Blazer S, Bader D, Yurman S, Dolfin T, Kogan A, Dollberg S, Arbel E, Goldberg M, Gur I, Naor N, Sirota L, Mogilner S, Zaritsky A, Barak M, Gottfried E (2000) Early postnatal dexamethasone treatment and increased incidence of cerebral palsy. Arch Dis Child Fetal Neonatal Ed 83:177-181

Sundberg M, Savola S, Hienola A, Korhonen L, Lindholm D (2006) Glucocorticoid hormones decrease proliferation of embryonic neural stem cells through ubiquitin-mediated degradation of cyclin D1. In J Neurosci 26:5402-5410

Tucker RP, Garner CC, Matus A (1989) In situ localization of microtubule-associated protein mRNA in the developing and adult rat brain. Neuron 2:1245-1256

Watterberg KL, Shaffer ML, Mishefske MJ, Leach CL, Mammel MC, Couser RJ, Abbasi S, Cole CH, Aucott SW, Thilo EH, Rozycki HJ, Lacy CB (2007) Growth and neurodevelopmental outcomes after early low-dose hydrocortisone treatment in extremely low birth weight infants. Pediatrics 120:40-48

Yeh TF, Lin YJ, Lin HC, Huang CC, Hsieh WS, Lin CH, Tsai CH (2004) Outcomes at school age after postnatal dexamethasone therapy for lung disease of prematurity. N Engl J Med 350:1304-1313

doi:10.1186/2193-1801-3-527

Cite this article as: Ninomiya et al: Glucocorticoids promote neural progenitor cell proliferation derived from human induced pluripotent stem cells. SpringerPlus 2014 3:527.

\section{Submit your manuscript to a SpringerOpen ${ }^{\odot}$ journal and benefit from:}

- Convenient online submission

- Rigorous peer review

- Immediate publication on acceptance

- Open access: articles freely available online

- High visibility within the field

- Retaining the copyright to your article

Submit your next manuscript at $\gg$ springeropen.com 